The Egyptian Journal of Hospital Medicine (October 2018) Vol. 73 (5), Page 6672-6682

\title{
Sutureless 23-gauge Versus Sutureless 20-gauge Pars Plana Vitrectomy Mohamed I.EL-Kasaby
}

Department of Ophthalmology, Faculty of Medicine for girls, Al-Azhar University, Cairo- Egypt

Corresponding author:Ammarelkasaby@yahoo.com, Mobile :+2 01001241403 - 010423513,email:

ammarelkasaby@yahoo.com

\section{Abstract}

Aim: To compare sutureless 23-gauge versus sutureless 20-gauge system for pars plana vitrectomy as regarding safety and efficacy in pars plana vitrectomy. Patients and methods: A prospective non -randomized interventional study comparing the two vitrectomy systems in a group of disease requiring uncomplicated vitreoretinal surgery was carried out at Nour- ELHayaha Eye Center (Cairo) between August, 2015 and June, 2017. Patients were divided into two groups. Group (A) 23 -gauge group: included thirty eyes of 20 patients, ten patients had bilateral pars plana vitrectomy (PPV), while in group (B): included twenty five eyes of 20patients, five patients had bilateral operations. Ocular examinations included measurements of best corrected visual acuity (BCVA) at a distance using a logarithm of the minimum angle of resolution (logMAR) scale, refractive status using an autorefractometer (KR-8100; Topcon corporation, Tokyo, Japan), IOP was measured pre and postoperative by Goldman applanation tonometry (CT-80; Topcon corporation, Tokyo, Japan), and fundus evaluation using an indirect ophthalmoscope were obtained. Surgical indication, outcome, intraoperative and postoperative complications were evaluated. Patients with vitreoretinal pathology such as preretinal membrane, vitreous haemorrhage with fibrovascular proliferation (FVP), persistent vitreous haemorrhage ,tractional retinal detachment, persistent macular edema or macular hole were enrolled in this study. Furthermore, postoperative subjective pain, conjunctival injection, retinal function and situation of retina were evaluated. Follow up was performed at the 1 st day, $1 \mathrm{st}$, 2nd week and $1 \mathrm{st}$, 3rd and 6th month after surgery. Results: All the fifty five eyes completed the regularly follow up visits up to 24 months. 55 eyes of 40 patients divided into 2 groups: Group (A) 30 eyes of 20 patients $(6$ males, $30 \%$ and 14 females, $70 \%$, the mean age of the participants \pm SD was $54.62 \pm 3.12$ years Range: 46-60 years;were treated with 23-gauge PPV .While in Group (B) twenty five eyes of 20 patients (13 males, $65 \%$ and 7 females, 35\%, the mean age of the participants \pm SD was $49.72 \pm 3.06$ years Range: 50-58 years; were treated with sutureless 20gauge PPV. The mean age of both groups \pm SD was 52.67 \pm 5.14 years (Range: 47-62 years). Statistically, the differences between both groups regarding age and sex were insignificant. Conclusion: Advantages of sutureless vitrectomy include a reduction in operating time, less subconjunctival adhesion facilitating any subsequent vitreoretinal surgery or filtration surgery

Keywords: Sutureless gauge vasectomy, Tractional retinal detachment, Fibrovascular proliferation.

\section{Introduction:}

The principles that guide the development of any given surgical procedure is the desire for less invasive approaches that will achieve the same or better outcomes. The advantages of smaller surgical incisions have resulted in faster postoperative rehabilitation ${ }^{(1)}$. Evolution of instrumentation used in pars plana Vitrectomy is desirable to minimize ocular trauma and improve post-operative comfort. Smaller instruments have been evolved to perform sutureless vitrectomy procedures for different indications. However, the

instruments used are fragile and less reusable thereby increasing the surgical cost. The illumination systems because of the smaller gauge are not very bright. Wound construction is the essential step in ensuring postoperative wound stability. Key points include an oblique, tunneled approach to ensure a valve-like effect as well as misalignment of conjunctival and scleral wounds by displacing conjunctiva during construction $^{(2)} .23$-gauge transconjunctival sutureless vitrectomy was developed by using an obliquely entering trocar cannular 
system and this evolution in vitreoretinal surgery has become increasingly popular in the last few years ${ }^{(3)}$.

20-gauge transconjunctival trocar system was described by Lafeta et al. They were inserted through the sclerostomy for the duration of the procedure that allowed repeated insertion and removal of 20-gauge instruments ${ }^{(4)}$.

Advantages of sutureless surgery include decreased operative times and decreased postoperative inflammation, early postoperative rehabilitation, improved patient comfort, and minimal conjunctival damage. Complications are based around wound competence, hypotony, and its relationship to endophthalmitis rates ${ }^{(5)}$.

Patients and methods:

A prospective non -randomized interventional study was carried out at NourEL-Hayaha Eye Center (Cairo) between August, 2015 and June, 2017.

55 eyes of 40 patients divided into 2 groups: All the fifty five eyes completed the regularly follow up visits up to 24 months. Group (A) 30 eyes of 20 patients (6 males, $30 \%$ and 14 females, $70 \%$, the mean age of the participants \pm SD was $54.62 \pm 3.12$ years Range: 46-60 years; were treated with 23gauge PPV .While in

Group (B) twenty five eyes of 20 patients (13 males, 65\% and 7 females, 35\%, the mean age of the participants \pm SD was 49.72 \pm 3.06 years Range: 50-58 years;were treated with sutureless 20-gauge PPV. The mean age of both groups \pm SD was $52.67 \pm 5.14$ years (Range: 47-62 years). Statistically, the differences between both groups regarding age and sex were insignificant. Symptomatic marked diminution of vision and vitreoretinal pathology such as preretinal membrane, vitreous haemorrhage with fibrovascular proliferation (FVP),persistent vitreous haemorrhage ,tractional retinal detachment, persistent macular edema or macular hole were enrolled in this study.

The study protocol was adhered to the tenets of declaration of Helisinki and was approved by the ethics board of AL- Azhar university .An informed written consent was taken from each participant in the study after a detailed explanation of the procedure and possible benefits and risks. A full history included medical history (duration of diabetes, controlled or not) other relative systemic diseases and family history of diabetes .Glycosylated hemoglobin were controlled in this study. A detailed clinical history that included the onset of visual disturbances and history of ocular diseases was obtained at the initial visit at which vitreoretinal pathology was detected. All patients underwent a full ocular examination included measurement of decimal and Snellen's visual acuity, slit lamp examination and indirect ophthalmoscopy. Special investigations in selected cases as B-scan ( in dense vitreous hemorrhage )to look for the presence of subhyaloid haemorrhage, fibrovascular proliferation(fig.1), evidence of tractional retinal detachment and for the state of optic disc head and biometry for all phakic eyes. Patients with a history of ophthalmic disorders associated with vitreoretinal pathology, such as uveitis and branch or central retinal vein occlusion, patients with gross ocular diseases that affects visual acuity (e.g. uncontrolled glaucoma and dense cataract) and patients with previous history of vitrectomy or those who had previous ocular procedures that involved conjunctival dissection or any healing disorder were excluded in this study. Furthermore, any patient with corneal pathology that hinders efficient visualization of posterior segment was excluded. Patients who failed to complete follow-up examinations one month after operation were also excluded. All patients underwent sutureless PPV by a single surgeon. A follow -up period of at least 6 months after vitrectomy, Spectral domain optical coherent tomography (SD OCT) images were obtained at the follow -up visits to determine the presence of an epiretinal membrane (ERM).

\section{Surgical procedure}

All the cases were prepared and draped in the standard fashion. Surgery was performed under local anesthesia with peribulbar block. 
Seclerotomy was done in two-step entry for 20and 23-gauge vitrectomy. A bent 20 or 23-gauge MVR blade was introduced into the conjunctiva-sclera in a beveled direction to create a 10 to 20 degrees angled incision and to obtain tunnels parallel to the corneoscleral limbus. The tunnel incision created in this fashion was left without a suture at the end of the operation. Subsequent intraoperative assessment included careful documentation of any surgical steps, instrumentation, and the gas used as the tamponading agent. All patients had undergone 3 port vitrectomy using Alcon Accurus (pneumatic vitreous cutter). Non-contact wide angle viewing system (BIOM) was used for visualization. Illumination was provided by xenon light, through 23-guage light pipe. The vacuum was set at $100 \mathrm{mmHg}$ to $400 \mathrm{mmHg}$ with bottle height of $50-150 \mathrm{~cm}$. The cut rate of the Microsurgical System of 1500-2500 cuts per minute was utilized in all cases.

The infusion line canuula was introduced to inferotemporal cannula. Wide angle fundus visualization was achieved using BIOM noncontact wide field imaging system. Great care was taken to remove all vitreous from around the internal opening of infusion cannula during vitrectomy. Core vitrectomy was performed and the posterior hyaloid was detached and removed in all cases. Peripheral vitreous base shaving with the help of good indentation. Pars plana vitrectomy with triamcinolone -assisted posterior vitreous detachment induction. (Kenacort-A; SmithKline Beecham Egypt L.L.C. An affiliated co. to GlaxoSmithKline,) was left standing for 15 minutes and the vehicle of triamcinolone acetonide was discarded. The remaining triamcinolone acetonide (40 mg) suspension was mixed with $5 \mathrm{ml}$ balanced salt solution(BSS) and then was used for the following procedure as a triamcinolone suspension. In selected cases; internal limiting membrane peeling (ILM) assisted by Brilliant blue $\mathrm{G}$ (BBG) dye was injected under air and left for 30 seconds to one minute ,air fluid exchange were done and the excess dye was removed, a scratch was made in the stained ILM by 23 gauge needle and flap was initiated ,ILM peeling was completed using 23 gauge ILM forceps. Silicone oil (100\% polydimethylsiloxane with a viscosity of 2000centistock) was used as an internal tamponade in all cases. Endolaser photocoagulation was done in all cases (fig.3,4).During removal of the cannulas at the end of the surgery, the eye was pressurized digitally to normal IOP, and the port sites were massaged for few seconds in a direction against that used during trocars insertion. The last step was to check the integrity of the ports to avoid postoperative leakage and suturing of the leaky ports was done when needed.

All patients underwent postoperative positioning; posturing was maintained for one week. Silicone oil removal was planned within 2 to 6 months of the initial surgery and was removed in all eyes. Follow up was performed postoperatively at one week, one month, 3 months, and 6 months .At each visit, best corrected visual acuity (BCVA), intraocular pressure, lens status, intraocular and post ocular complications and anatomical status of the retina were assessed.

\section{Statistical Analysis}

We calculate sample size according to Raosoft and all statistical calculations were done using SPSS (Statistical Package for the Social Science version 20.00; SPSS Inc., Chicago, Illinois, USA). Quantitative data with parametric distribution were done using Analysis of variance $t$ test. The confidence interval was set to $95 \%$ and the margin of error accepted was set to $5 \%$. The p-value was considered non significant (NS) at the level of $>0.05$, significant at the level of < $0.05,0.01$ and highly significant at the level of $<0.001$. Pearson linear correlation coefficient (r) was estimated to show the relationship between quantitative parameters.

Results :

All the fifty five eyes (tables:1,2):completed the regularly follow up visits up to 24 months. 55 eyes of 40 patients divided into 2 groups :Group (A)30 eyes of 20 patients treated with 23 -gauge 
PPV and Group (B) twenty five eyes of 20patients treated with sutureless 20-gauge PPV; Group A, (table:1)included 30 eyes in 20 patients (6 males, $30 \%$ and 14 females, $70 \%$ ). Group $\boldsymbol{B}$ included 25 eyes in 20 patients (13 males, 65\% and 7 females, $35 \%)$. Mean age of both groups \pm SD was $52.67 \pm 5.14$ years (Range: $47-62$ years). In group $A$, the mean age of the participants \pm SD was 54.62 \pm 3.12 years (Range: $46-60$ years), while in group $\boldsymbol{B}$ the mean age of the participants \pm SD was $49.72 \pm 3.06$ years (Range: 50-58 years). Statistically, the differences between both groups regarding age and sex were insignificant.

In group A: 12 eyes (40\%) had vitreous haemorrhage with fibrovascular proliferation FVP (fig.1,2),10 eyes $(33.33 \%$ ) had vitreous haemorrhage with tractional retinal detachment (TRD), and 8 eyes $(26.66 \%)$ had persistent vitreous haemorrhage.

In group B: 10 eyes (40\%) had persistent vitreous haeorrahge with epiretinal membrane(ERM)(5,6) , 8 eyes $(32 \%)$ had tractional retinal detachment, and 2 eyes $(8 \%)$ had old retinal vein occlusion with persistent vitreous haemorrhage and 5 eyes (20\%) had vitreous haemorrhage with tractional retinal detachment (TRD).

The main comparative results between the 23-gauge and the 20-gauge group are surgical timing, visual acuity, pain and tenderness, conjunctival injection and intraocular pressure .

\section{As regarding visual acuity:}

In group $(\boldsymbol{A})$ (table:1):Visual acuity ranged from HM to 6/36, with median visual acuity $6 / 60,15$ patients $(50.0 \%)$ were already suffering from visually insignificant cataract and 3 patients (20\%) were pseudophakic and 12 patients underwent phacovitrectomy with IOL. The time of introduction of the microcannulas and the infusion cannula was about 2 minutes in all cases (ranging from 100 to 130 seconds). Wound sealing was taken about 1 minute in all cases (ranging from 45 to 80 seconds). Mean visual acuity was calculated after transformation of Snellen's visual acuity into rank system for quantitative analysis statistical purposes.
The visual acuity changed from baseline during the 1st month after surgery and showed no significant differences (NS) in both groups as shown in the Wilcoxon Rank Sum Test.

In group (B) (table:2): The preoperative best corrected visual acuity (BCVA) ranged from 0.005 to 0.500 with mean of 0.083 in all patients. Mean preoperative Log MAR VA was $1.68 \pm 0.23$. It changed to $0.56 \pm$ 0.23 postoperatively $(0.65 \pm 0.22)$. Postoperative visual acuity improved in 18 eyes $(72 \%)$, was stable in 5 eyes $(20 \%)$ and decreased in 2 eyes (8\%). Postoperative visual acuity was $6 / 18$ (Log MAR 0.3).

\section{As regarding duration of surgery}

A highly significant (HS) shorter duration of wound opening in the $\boldsymbol{A}$ group $(\mathrm{p}<0.001)$ as well as wound closing $(\mathrm{p}<0.001)$ compared with the 20-gauge system. Wound opening time was around 2 minutes with mean timing of $2 \pm 0$ minutes in the B group while wound closure time was around 1 minute with mean timing of $1 \pm 0$ minute in the $\boldsymbol{A}$ group .Vitrectomy duration was significantly $(p<0.025)$ longer in the 23 gauge system vitrectomy and manipulation time ranged from 40 to 80 minute with mean timing of $66.13 \pm 11.92$ minutes.

\section{As regarding Conjunctival injection}

Conjunctival was significantly lower in the $\boldsymbol{A}$ group $(\mathrm{p}<0.001)$ and the postoperative local inflammation from suture material. Also smaller conjunctival and scleral wound caused less inflammation. Paired $t$ Test showed that conjunctival inflammation improvement in the first postoperative week was highly significant (HS) in both groups. In the first postoperative day, the $\boldsymbol{B}$ group conjunctival injection scale ranged from 0 (no conjunctival injection) to 4 (severe conjunctival injection)according to Gioia et al.(6).Mean conjunctival injection scale was $0.87 \pm 0.83$.Also Subjective postoperative pain was significantly lower in the $\boldsymbol{A}$ group than $\boldsymbol{B}$ group. In addition Wilcoxon rank sum test showed that this difference was highly significant (HS) between both groups.

As regarding pain: Degree of pain(table:3) conjuctival injection classified as no pain (0) 
,mild pain (1),moderate pain (2), severe pain(3) and unbearable pain(4) and conjunctival injection as mild ,moderate and severe. In the first postoperative day, the A group pain and tenderness scale ranged from 0 grade (no pain) to grade 4 (severe pain). The mean pain and tenderness scale was $0.87 \pm 0.74$. At the first postoperative week, the A group pain and tenderness scale ranged from 0 grade (no pain) to grade 4 (severe pain). The mean pain and tenderness scale was $0.11 \pm 0.15$.

Mean pain and tenderness scale was $0.87 \pm 0.7$ In the first postoperative day. At the first postoperative week, the $\boldsymbol{A}$ group pain and tenderness scale ranged from 0 (no pain) to 1 (mild pain). The mean pain and tenderness scale was $0.13 \pm 0.35$.Conjunctival injection was significantly lower in the 23gauge group $(\mathrm{p}<0.001)$ compared with the $\boldsymbol{B}$ group. In addition Wilcoxon Rank Sum Test showed that this difference was highly significant (HS). Paired t Test showed that conjunctival inflammation improvement in the first postoperative week was highly significant (HS) in both groups. In the first postoperative day, the $\boldsymbol{A}$ group conjunctival injection scale ranged from 0 (no conjunctival injection) to 4 (severe conjunctival injection). The mean conjunctival injection scale was $0.76 \pm 0.13$.

\section{As regarding $I O P$ :}

In group A: The intraocular pressure IOP, between $12 \mathrm{mmHg}$ to $19 \mathrm{mmHg}$ with mean IOP $15.3 \mathrm{mmHg}$. At the first postoperative day, the IOP dropped below $12 \mathrm{mmHg}$ in 14 cases $(46.6 \%)$, IOP was $>22 \mathrm{mmHg}$ in 6 cases $(20 \%)$. Mean IOP at the 1 st day was $14.11 \pm 1.5$. At the first postoperative week, IOP ranged from 10 to $16 \mathrm{mmHg}$, with mean IOP of $15 \mathrm{mmHg}$. Mean IOP after the 1st week was $12.21 \pm 3.1$.

In group $B$ : Mean preoperative IOP) was $14.32 \pm 1.34 \mathrm{mmHg}$ and was $11.64 \pm 5.21$ $\mathrm{mmHg}$ one day postoperatively. It changed to $13.6 \pm 1.25 \mathrm{mmHg}$ one month post operatively. Two eyes had postoperative increase in IOP $(8 \%)$ that controlled with medical treatment. Transient increase in IOP was realized in 8 eyes (32\%). Medical treatment was successful in managing those cases without need for glaucoma filtering surgery.

\section{As regarding cataract}

The incidence of postoperative cataract formation in our study is comparable to the previous results of other research. Cataract occurred in almost all phakic eyes with silicone oil internal tamponade. Insignificant lens changes became significant which required cataract extraction.

Cataract extraction (phacoemulsification) with IOL implantation was done during silicone oil removal at least six months after surgery.

\section{Post-operative:}

No cases of postoperative endophthalmitis nor choroidal hemorrhage. Slit lamp assessment of the lens in our patients revealed clear lens in 16 eyes (64\%), early visually insignificant lens changes in 6 eyes (24\%) and pseudophakia in 3 eyes (12\%).

Most common postoperative complication after vitrectomy was cataract formation, which occurred in $24(63.2 \%)$ of the 38 phakic eyes.

All patients had a flat retina in the second postoperative day that continued so till removal of the silicone oil except two eyes in the group $(A)$ showed moderate vitreous hameorrhage , 2 cases (6.6\%) showed moderate vitreous haemorrhage on the first postoperative day which resolved spontaneously and one case developed retinal detachment which occurred in one case $(3.33 \%)$ after silicone removal and managed by a re surgery and silicone oil injection.

In the group $B$ two eyes developed retinal detachment after removal of silicon which was required re intervention .The primary anatomical success rate in Group (A) was 96.66\% and in Group (B) was 92\%.No cases of postoperative endophthalmitis nor choroidal hemorrhage. No lens touch was present in any of these surgeries. None of the cases required resurgery in the 2 nd postoperative day. 
Table (3): Pain and conjunctival injection after vitrectomy

\begin{tabular}{|l|l|l|}
\hline Score of pain & 23-gauge & 20-gauge \\
\hline 0 & $80 \%(24 \mathrm{eyes})$ & $72 \%(18 \mathrm{eyes})$ \\
\hline 1 & $16.6 \%(5 \mathrm{eyes})$ & $16 \%$ (4eyes) \\
\hline 2 & $3.33 \%(1)$ & $8 \%$ (2eyes \\
\hline 3 & $0.00 \%$ & $3 \%(1$ eye $)$ \\
\hline 4 & $0.005 \%$ & \\
\hline Conjunctival injection & & \\
\hline No & $80 \%(24 \mathrm{eyes})$ & $72 \%(18$ eyes $)$ \\
\hline Mild & $10.00 \%(3 \mathrm{eyes})$ & $16 \%(4$ eyes $)$ \\
\hline Moderate & $10.00 \%(3 \mathrm{eyes})$ & $12 \%(3$ eyes $)$ \\
\hline Severe & 0.00 & 0.00 \\
\hline
\end{tabular}

Table (1): Master sheet of 23 -gauge vitrectomy

\begin{tabular}{|c|c|c|c|c|c|c|c|c|c|}
\hline & Age & $\begin{array}{l}\text { Lens } \\
\text { satus }\end{array}$ & $\begin{array}{l}\text { Preop. } \\
\text { BCVA }\end{array}$ & $\begin{array}{l}\text { Postop. } \\
\text { BCVA }\end{array}$ & $\begin{array}{l}\text { Log } \\
\text { MAR }\end{array}$ & $\begin{array}{l}\text { Time of } \\
\text { surgery }\end{array}$ & $\begin{array}{l}\text { Preop. } \\
\text { IOP }\end{array}$ & $\begin{array}{l}2^{\text {nd }} \text { day } \\
\text { IOP }\end{array}$ & $\begin{array}{l}\text { Postop. } \\
\text { IOP }\end{array}$ \\
\hline 1 & 37 & Cataract & HM & $6 / 24$ & 0.3 & $50 \mathrm{~min}$ & 15 & 21 & 13 \\
\hline 2 & 25 & early & $1 / 60$ & $6 / 18$ & 0.3 & $65 \mathrm{~min}$ & 13 & 14 & 16 \\
\hline 3 & 35 & Cataract & $\mathrm{CF}$ & $6 / 60$ & 0.1 & $80 \mathrm{~min}$ & 13 & 11 & 13 \\
\hline 4 & 47 & Cataract & $2 / 60$ & $6 / 24$ & 0.3 & $65 \mathrm{~min}$ & 17 & 19 & 21 \\
\hline 5 & 44 & Cataract & $2 / 60$ & $6 / 12$ & 0.4 & $65 \mathrm{~min}$ & 15 & 14 & 21 \\
\hline 6 & 28 & early & $6 / 60$ & $6 / 18$ & 0.3 & $65 \mathrm{~min}$ & 11 & 22 & 15 \\
\hline 7 & 55 & Pseudo & $6 / 60$ & $6 / 18$ & 0.5 & $75 \mathrm{~min}$ & 12 & 15 & 19 \\
\hline 8 & 24 & Cataract & HM & $6 / 24$ & 0.4 & $60 \mathrm{~min}$ & 14 & 12 & 17 \\
\hline 9 & 52 & Cataract & $\mathrm{CF}$ & $6 / 24$ & 0.2 & $75 \mathrm{~min}$ & 11 & 15 & 12 \\
\hline 10 & 28 & early & $1 / 60$ & $6 / 24$ & 0.1 & $55 \mathrm{~min}$ & 14 & 19 & 20 \\
\hline 11 & 59 & Cataract & $2 / 60$ & $2 / 60$ & 0.05 & $80 \mathrm{~min}$ & 16 & 16 & 14 \\
\hline 12 & 21 & early & $2 / 60$ & $6 / 12$ & 0.4 & $65 \mathrm{~min}$ & 15 & 14 & 16 \\
\hline 13 & 54 & Pseudo & $\mathrm{CH}$ & $6 / 24$ & 0.5 & $55 \mathrm{~min}$ & 13 & 14 & 18 \\
\hline 14 & 18 & early & $6 / 60$ & $6 / 14$ & 0.2 & $75 \mathrm{~min}$ & 13 & 19 & 14 \\
\hline 15 & 50 & Pseudo & $1 / 60$ & $6 / 60$ & 0.5 & $65 \mathrm{~min}$ & 12 & 11 & 12 \\
\hline 16 & 32 & Early & $\mathrm{CF}$ & $6 / 24$ & 0.3 & $75 \mathrm{~min}$ & 13 & 21 & 19 \\
\hline 17 & 56 & Cataract & $6 / 24$ & $6 / 18$ & 0.3 & $60 \mathrm{~min}$ & 13 & 15 & 16 \\
\hline 18 & 45 & Early & $\mathrm{CF}$ & $6 / 18$ & 0.3 & $55 \mathrm{~min}$ & 10 & 5 & 11 \\
\hline 19 & 43 & Cataract & $6 / 60$ & $6 / 12$ & 0.4 & $55 \mathrm{~min}$ & 14 & 11 & 14 \\
\hline 20 & 20 & Early & HM & $6 / 24$ & 0.3 & $65 \mathrm{~min}$ & 10 & 5 & 11 \\
\hline 21 & 30 & Early & HM & $6 / 12$ & 0.5 & $60 \mathrm{~min}$ & 11 & 5 & 10 \\
\hline 22 & 34 & Early & $6 / 18$ & $6 / 18$ & 0.5 & $50 \mathrm{~min}$ & 14 & 10 & 13 \\
\hline 23 & 19 & Cataract & $1 / 60$ & $6 / 12$ & 0.8 & $60 \mathrm{~min}$ & 11 & 15 & 19 \\
\hline 24 & 50 & Early & $1 / 60$ & $6 / 60$ & 1.0 & $60 \mathrm{~min}$ & 13 & 15 & 12 \\
\hline 25 & 43 & Cataract & $3 / 60$ & $6 / 18$ & 0.5 & $60 \mathrm{~min}$ & 13 & 11 & 13 \\
\hline 26 & 27 & Cataract & $1 / 60$ & $6 / 12$ & 0.5 & 65 & 10 & 21 & 18 \\
\hline 27 & 34 & early & HM & $6 / 24$ & 0.2 & $60 \mathrm{MIN}$ & 23 & 18 & 14 \\
\hline 28 & 21 & early & HM & $6 / 12$ & 0.3 & $50 \mathrm{~min}$ & 14 & 26 & 14 \\
\hline 29 & 30 & Early & $\mathrm{CF}$ & $6 / 18$ & 0.3 & $70 \mathrm{~min}$ & 14 & 14 & 13 \\
\hline 30 & 19 & early & HM & $6 / 18$ & 0.3 & $55 \mathrm{~min}$ & 14 & 18 & 13 \\
\hline
\end{tabular}


Table (2): Master sheet of 20 -gauge vitrectomy

\begin{tabular}{|c|c|c|c|c|c|c|c|c|c|}
\hline & Age & Lens & Preop. & Postop. & $\log$ & Time of & Preop. & $2^{\text {nd }}$ day & Postop. \\
\hline 1 & 58 & Early & $6 / 60$ & $6 / 36$ & 0.8 & $50 \mathrm{~min}$ & 14 & 10 & 15 \\
\hline 2 & 59 & Pseudo & $5 / 60$ & $6 / 36$ & 0.8 & $50 \mathrm{~min}$ & 14 & 9 & 15 \\
\hline 3 & 48 & Early & HM & $6 / 60$ & 1.0 & $50 \min$ & 14 & 9 & 13 \\
\hline 4 & 19 & Clear & $1 / 60$ & $6 / 12$ & 0.3 & $60 \mathrm{~min}$ & 15 & 11 & 14 \\
\hline 5 & 28 & Clear & $6 / 36$ & $6 / 36$ & 0.8 & $60 \mathrm{~min}$ & 13 & 9 & 11 \\
\hline 6 & 30 & Clear & $5 / 60$ & $6 / 36$ & 0.8 & $50 \mathrm{~min}$ & 13 & 12 & 13 \\
\hline 7 & 62 & Clear & $6 / 60$ & $6 / 24$ & 0.6 & $50 \min$ & 16 & 10 & 15 \\
\hline 8 & 40 & Clear & HM & $6 / 18$ & 0.5 & $70 \mathrm{~min}$ & 12 & 12 & 13 \\
\hline 9 & 23 & Clear & $6 / 36$ & $6 / 24$ & 0.6 & $50 \mathrm{~min}$ & 14 & 9 & 14 \\
\hline 10 & 60 & Pseudo & $6 / 36$ & $6 / 24$ & 0.6 & $50 \mathrm{~min}$ & 14 & 9 & 14 \\
\hline 11 & 33 & Clear & $6 / 36$ & $6 / 36$ & 0.8 & $60 \mathrm{~min}$ & 13 & 9 & 11 \\
\hline 12 & 57 & Clear & $5 / 60$ & $6 / 36$ & 0.8 & $50 \min$ & 13 & 12 & 13 \\
\hline 13 & 59 & Clear & $6 / 60$ & $6 / 24$ & 0.6 & $50 \mathrm{~min}$ & 16 & 10 & 15 \\
\hline 14 & 20 & Pseudo & HM & $6 / 60$ & 1.0 & $50 \mathrm{~min}$ & 14 & 9 & 13 \\
\hline 15 & 56 & clear & HM & $6 / 60$ & 1.0 & $50 \mathrm{~min}$ & 14 & 9 & 13 \\
\hline 16 & 53 & Early & $6 / 60$ & $6 / 36$ & 0.8 & $60 \mathrm{~min}$ & 13 & 11 & 12 \\
\hline 17 & 20 & clear & $1 / 60$ & $6 / 12$ & 0.3 & $60 \mathrm{~min}$ & 14 & 10 & 14 \\
\hline 18 & 50 & clear & HM & $6 / 60$ & 1.0 & $50 \mathrm{~min}$ & 14 & 9 & 13 \\
\hline 19 & 33 & clear & $1 / 60$ & $6 / 60$ & 1.0 & $70 \mathrm{~min}$ & 13 & 5 & 14 \\
\hline 20 & 60 & Early & $6 / 36$ & $6 / 36$ & 0.8 & $60 \mathrm{~min}$ & 14 & 12 & 12 \\
\hline 21 & 19 & clear & HM & $6 / 60$ & 1.0 & $50 \min$ & 14 & 9 & 13 \\
\hline 22 & 36 & clear & $\mathrm{CF}$ & $6 / 18$ & 0.5 & $60 \mathrm{~min}$ & 14 & 10 & 14 \\
\hline 23 & 22 & clear & $6 / 12$ & $6 / 18$ & 0.5 & $50 \mathrm{~min}$ & 15 & 11 & 12 \\
\hline 24 & 62 & Early & $1 / 60$ & $5 / 60$ & 1.07 & $50 \mathrm{~min}$ & 10 & 12 & 12 \\
\hline 25 & 55 & Early & $6 / 60$ & $6 / 36$ & 0.8 & $60 \mathrm{~min}$ & 13 & 11 & 12 \\
\hline
\end{tabular}

20gauge vitrectomy.

Fig. (2) :Grasping of membrane by vitreoretinal forceps 20 gauge 


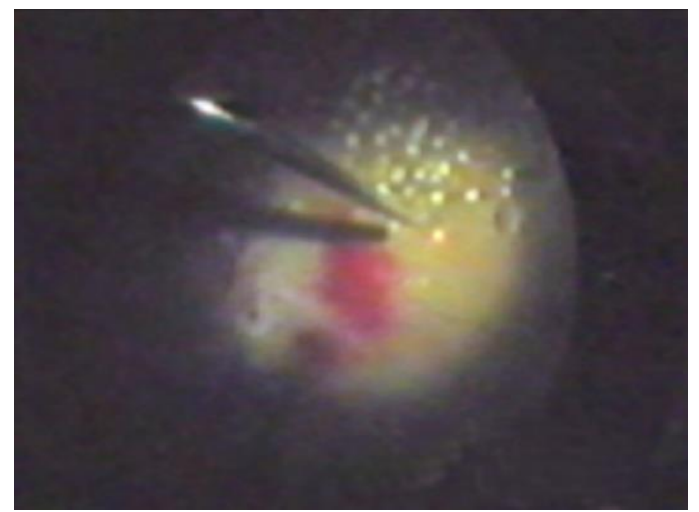

Fig. (3) :Endolaser 20gauge vitrectomy

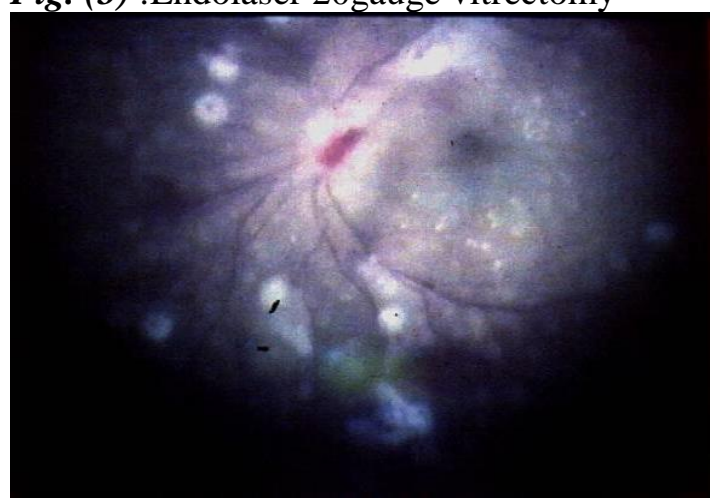

Fig. (4) $: 2^{\text {nd }}$ day postoperative

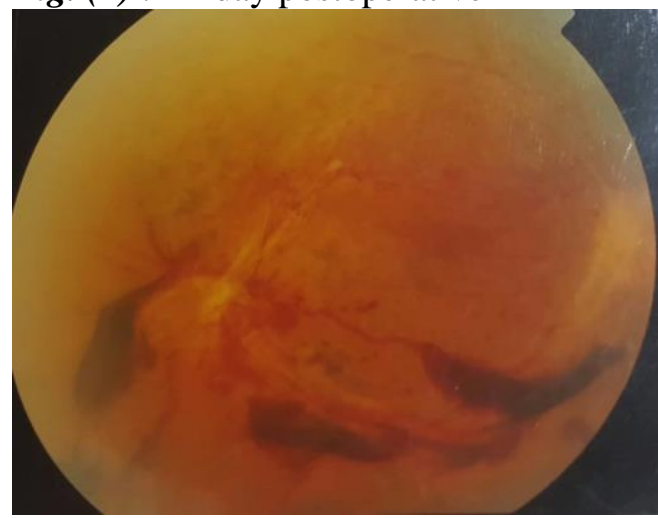

Fig. (5) : Epiretinal membrane with vitreous haemorrhage

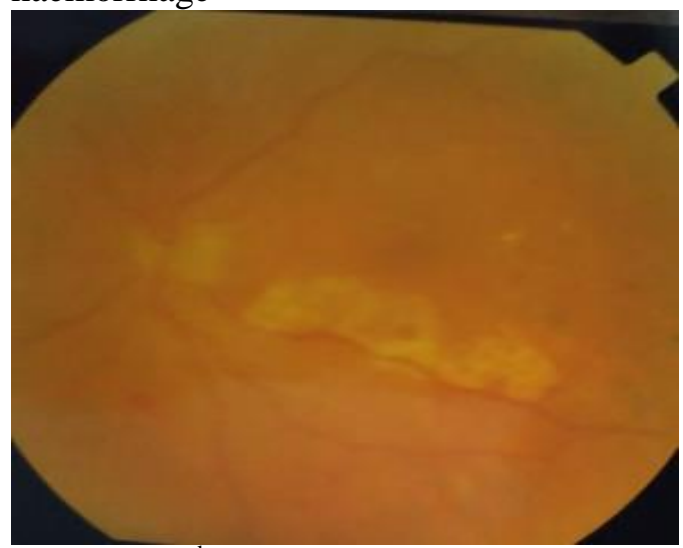

Fig. (6) $: 2^{\text {nd }}$ day postoperative

\section{Discussion:}

Sutureless vitrectomy has rapidly been accepted, the size and structure of the wound makes the incision self-sealing, safe and no needs for sutures at the end of the procedure. Advantages include decreased operative times simplifying the surgical procedure, minimizing surgically induced trauma; decreased postoperative inflammation, early postoperative rehabilitation, improved patient comfort and minimal conjunctival damage.

In the present study, Vitrectomy duration was significantly longer in the 23-gauge system vitrectomy and manipulation time ranged from 40 to 80 minute with mean timing of $66.13 \pm 11.92$ minutes with no significant (NS) difference noticed between the two groups regarding the duration of retinal manipulation. This study was closely related to Fujii et al. ${ }^{(\mathbf{1})}$ who reported that, a significantly reduced total operating duration using the 23 gauge system which is in contrast to our findings. A possible explanation could be that in several cases (i.e. epiretinal membrane peeling) no vitrectomy was performed before or after retinal manipulation.

In this current study, mean preoperative Log MAR VA was obvious that there were significant increase in vision which was related to Yanyali et al. ${ }^{(7)}$ who reported that mean $\log$ MAR visual acuity was $2.01 \pm$ 0.47 preoperatively and $1.3 \pm 0.5$ one month postoperatively. The difference in mean $\log$ MAR visual acuity to our results may be due to poor preoperative visual acuity in their study but the overall outcome is significant improvement in vision in both studies. The slight difference may be due to the case selection criteria which favored more simple and less advanced cases with better preoperative visual acuity .On the other hand, Ibarra et al. ${ }^{(8)}$ retrospectively studied 45 consecutive patients of 22-gauge vitrectomy and found mean overall preoperative visual acuity versus last postoperative visual acuity was 4/60 and $6 / 24$, respectively $(\mathrm{P}<.0001$ ), compared to median visual acuity of $4 / 60$ preoperatively 
and 6/36 postoperatively in our study. This slight difference might be due to the variability in case selection.

Lakhanpal et al. ${ }^{(9)}$ reported that; median visual acuity study improved from $5 / 60$ preoperatively to $6 / 18$ at final visit. Mean follow-up was 33.8: $:$ :9.7 weeks, and all eyes were observed for a minimum of 12 weeks. In our study median visual acuity improved from $4 / 60$ preoperatively to $6 / 36$ after 1 month of follow up.

The primary anatomical success rate in Group (A) was $96.66 \%$ and in Group (B) was $92 \%$. Re detachment may be due to incomplete shaving of the vitreous base or undiscovered minute holes or tears. They had re surgery and the retina was flat after surgery in both of them. This study was closely related to a study was done by

Eckardt ${ }^{(3)}$ and by Sable et al. ${ }^{(10)}$ on consecutive series of 41 patients, 8 of them had rhegmatogenous retinal detachment. The single operation anatomical success rate of $92.68 \%$ was reported in this series which is comparable to this current study.

In the present study, conjunctival injection was significantly lower in the 23gauge group $(\mathrm{p}<0.001)$ compared with the 20 -gauge group, it was obvious in the 25 gauge group that the postoperative local inflammation from suture material. Also smaller conjunctival and scleral wound caused less inflammation. Paired $t$ Test showed that conjunctival inflammation improvement in the first postoperative week was highly significant (HS) in both groups. In addition; subjective postoperative pain was significantly lower in the 23-gauge group $(p<0.002)$ compared with the 20 gauge group, smaller conjunctival and scleral wound caused less irritation. In addition Wilcoxon rank sum test showed that this difference was highly significant (HS). Wound architecture is the most important aspect of this surgery and may be followed by hypotony and potentially increase such complications as endophthalmitis and hypotonic maculopathy. However, the learning curve is short enough for the adaptable surgeon.
Also, it offers an economic advantage to surgeons to use the existing 20-gauge instrumentation. When suturing was required, a single transconjunctival absorbable stitch in the end of surgery was adequate.

Rizzo et al. ${ }^{(11)}$ compared 23 gauge group versus 20 gauge group: reporting that postoperative pain significantly lower in the 25-gauge group. The postoperative inflammatory score at the follow-ups showed significantly lower inflammation in the 25-gauge group. This is consistent with our findings. In a prospective randomized clinical trial similar to our study, Lukas et al. ${ }^{(12)}$ compared the 25-gauge and the 20gauge systems and found that the conjunctival injection and subjective postoperative pain score showed significantly lower irritation in the 25-gauge group $(\mathrm{p}<0.001)$. In addition; in Christopher et al. (13) study no detectable inflammation was noted in any eyes by 4 weeks postoperatively. These results are consistent with our study.

Mean preoperative IOP) was $14.32 \pm 1.34$ $\mathrm{mmHg}$ and was $11.64 \pm 5.21 \mathrm{mmHg}$ one day postoperatively. It changed to $13.6 \pm 1.25$ $\mathrm{mmHg}$ one month post operatively. Two eyes had postoperative increase in IOP $(8 \%)$ that controlled with medical treatment. Transient increase in IOP was realized in 8 eyes (32\%). Medical treatment was successful in managing those cases without need for glaucoma filtering surgery this study was closely related to Mario et al. ${ }^{(14)}$ and Moon et al. ${ }^{(15)}$.

Cataract extraction (phacoemulsification) with IOL implantation was done during silicone oil removal at least six months after surgery this study was disagree with study was done by Yanyali et al. ${ }^{(7)}$ who reported that, cataract formation or progression $(38.5 \%)$ and also dis agree with Sonar et al. ${ }^{(16)}$ reported cataract formation in the 2 nd group of their study cases in 9 eyes $(45 \%)^{(16)}$. The high incidence of cataract formation or progression in the present study may be due to late removal of silicone oil. This current study had no major complications as choroidal detachment or 
endophthalmitis agree with a study reported by Jain et al. ${ }^{(7)}$. and Yanyali et al. studies ${ }^{(18)}$. No lens touch was observed in this current study while Mittal et al. ${ }^{(18)}$ reported lens touch in one eye $(1.9 \%)$.

In the present study, No serious postoperative complications were reported such as postoperative endophthalmitis or choroidal detachment. This study was agree with study reported by Abdel Alim and Abdrabbo $^{(19)}$.

Conclusions:

Advantages of sutureless vitrectomy include a reduction in operating time, less subconjunctival adhesion facilitating any subsequent vitreoretinal surgery or filtration surgery, a more aesthetically pleasing appearance of the eye, does not compromise the surgical or visual outcome of internal posterior segment surgery.

Compliance with ethical standards.

Conflict of interest : certifies that he has no affiliations with or involvement in any organization or entity with any financial interest in the subject matter or materials discussed in this manuscript.

\section{References :}

1. Fujii GY, de Juan E Jr, Humayun MS et al. (2002): A new 25-gauge instrument system for transconjunctival sutureless vitrectomy surgery. Ophthalmology, 109:1807-1812.

2. Guajardo L, Esteban P and Guezala $T$ (2006). Oblique sclerotomy technique for prevention of incompetent wound closure in transconjunctival vitrectomy. Am J Ophthalmol., 141(6):1154-1156.

3. Eckardt C(2005): Transconjunctival sutureless 23-gauge vitrectomy. Retina, 25:208- 211.

4. Lafeta AP and Claes $C$ (2007): Twenty gauge transconjunctival sutureless vitrectomy trocar system. Retina, 27:1136-1141.

5. Gosse E, Newsom $R$ and Lochhead $J(2013)$ : Changes in day one postoperative intraocular pressure following sutureless 23-gauge and conventional 20-gauge pars plana vitrectomy. Open Ophthalmol J., 7:4247.

6. Gioia L, Prandi E, Codenotti $M$ et al.(2000): Vitreo retinal surgery a double study .Anesth Analg.,89:739-42.

7. Lorenzo LG, Jeslis $P E$ and Miguel AT (2006): Oblique Sclerotomy Technique for Prevention of Incompetent Wound Cosure in Transconjunctival 25-Gauge Vitrectomy. Am J Ophthalmol., 141: 1154-1156.

8. Yanyali A, Celik G, Dincyildiz A et al.( 2012): Primary 23-gauge vitreoretinal surgery for rhegmatogenous retinal detachment. Int J Ophthalmol ., 5(2):226-230.

9. Ibarra MS, Hermel M, Prenner JL et al.(2005): Long-term outcomes of transconjunctival sutureless 25-gauge vitrectomy. Am J Ophthalmol .,139:8316.

10. Lakhanpal RR, Humayun MS, de juan $E$ et al.( 2005):Outcome of 140 consecutive cases of 25-gauge transconjnctival surgery for posterior segment disease. Ophthalmology, 112:817-24.

11. Sable A, John $R$, Narendran $V$ et al.(2010): 23-gauge transconjunctival sutureless vitrectomy for primary rhegmatogenous retinal detachment. AIOC., 576-579.

12. Rizzo S, Genovesi-Ebert F, Murri $S$ et al.(2006): 25-gauge, sutureless vitrectomy and standard 20-gauge pars plana vitrectomy in idiopathic epiretinal membrane surgery: a comparative pilot study. Graefe's Arch Clin Exp Ophthalmol., 244: 472-9.

13. Lukas K, Barbara W, Ulrike $S$ et al.( 2007): 25-gauge vs. 20-gauge system for pars plana vitrectomy: a prospective randomized clinical trial. $\mathrm{Br} \quad J$ Ophthalmol .,91: 945-48.

14. Christopher D, Riemann M, Daniel M et al.(2007): Outcomes of 140 Consecutive Cases of 25 Gauge Transconjunctival Surgery for Posterior Segment Disease. Retina, 27: 296-303. 
15. Mario R, Ronald D, Groenwald C et al.(2012): Primary 23-gauge sutureless vitrectomy for rhegmatogenous retinal detachment. Indian J Ophthalmol. , 60(1):29-33.

16. Moon H, Sohn HJ, Lee DY et al.(2015): Combined 23-gauge sutureless vitrectomy and clear corneal phacoemulsification for rhegmatogenous retinal detachment repair. Int J Ophthalmol., 8(1):122-127.

17. Sonar S, Citirik M, Beyazyildiz $E$ et al.( 2015): 23-gauge vitrectomy and silicone oil tamponade with and without phacoemulsification in rhegmatogenous retinal detachment. Int J Clin Exp Med ., 8(3):4257-4262.
18. Jain $P$, Nagpal $M$, Nagpal $K$ et al.(2010): Safety and efficacy of small gauge (TSV) With Expanding Indications. AIOC., 624-626.

19. Mittal S, Kaur K, Thind JS et al.(2010): 20-gauge transconjunctival sutureless vitrectomy: Possibility and Limitations. AIOC.,657-658.

20. Abdel-Alim A and Abdrabbo M (2013): Outcome of 20-gauge transconjunctival cannulated sutureless vitrectomy using silicone oil or air tamponade. Clinical Ophthalmology , 7: 379-384. 